\title{
Teaching Natural Resource Management-Teaching Techniques and Difficulties in Greek Vocational Lyceum: A Case Study
}

\author{
Marios Koutsoukos ${ }^{1} \&$ Antonios Mouratidis $^{2}$ \\ ${ }^{1}$ School of Agriculture, Aristotle University of Thessaloniki, Greece \\ ${ }^{2}$ School of Geology, Aristotle University of Thessaloniki, Greece \\ Correspondence: Marios Koutsoukos, School of Agriculture, Aristotle University of Thessaloniki, Greece. E-mail: \\ koutsoukos.marios@gmail.com
}

Received: September 10, 2015 Accepted: October 19, 2015 Online Published: March 23, 2016

doi:10.5539/ies.v9n4p20

URL: http://dx.doi.org/10.5539/ies.v9n4p20

\begin{abstract}
The aim of the present study is to investigate the teaching techniques applied, as well as the difficulties, with which educators in teaching Natural Resource Management are confronted. For research purposes, a case study was conducted on teaching Natural Resource Management in the Third Grade of Vocational Lyceum (EPAL) in Northern Greece. It was established that the teachers of the aforementioned subject make use of a range of experiential and active teaching techniques. On the other hand, the major difficulty faced by teachers is the lack of updated textbooks and training on the subject.
\end{abstract}

Keywords: teaching, natural resource management, secondary vocational education, teaching techniques, Greece

\section{Introduction}

As early as ancient times, people used the natural resources in their environment to survive and prolong their lives. A natural resource is considered any element or material the primary form of which is natural and has been assessed to be useful for one or more purposes within the context of human activities (Jones, 2003). One of the most common approaches classifies natural resources in three main categories: i) renewable (e.g. solar, wind, hydro power), ii) non-renewable (e.g. fossil fuels, minerals) and iii) potentially renewable (e.g. fresh water, fertile soil, biodiversity) (Voutsinos, Kalkanis, Kosmas, \& Soutsos, 2003).

Over the last few decades, irrational use of natural resources has caused several environmental problems in numerous regions all over the world (Gylfason, 2001). This fact, in combination with the rapid developments in technology, science and economy has brought forth the issue of sustainable management of natural resources (Jones, 2003). Undoubtedly prudent management requires relevant knowledge and skills (Littledyke, 2008; Jones, 2003). In other words, in order to effectively manage any natural resource, one should first be aware of its individual characteristics and qualities; and such knowledge can largely be derived from educational processes.

In this context, many countries have introduced into their education systems subjects pertaining to natural resource management, aiming at promoting environmental awareness among students and thus their future active citizens (Gylfason, 2001). Such subjects underline the relationship between contemporary socioeconomic reality and natural environment. Moreover, they aim at shaping students' critical thinking, thus enabling them to thoroughly study the various issues relevant to natural resource management (Dimitriou, 2009).

At the same time, several viewpoints on modern teaching approaches have been expressed on this subject matter, especially to formal education, both primary and secondary (Michail, A. Stamou, \& P. Stamou, 2007; Carrier, 2009; Ballantyne \& Packer, 2009). Since the way a subject is taught has a significant impact on its effectiveness, contemporary approaches focus on the use of experiential and learner-centered teaching techniques (Wurdinger \& Carlson, 2010). Thus, knowledge and skill acquisition on the individual aspects of natural resource management is directly linked with the use of applicable teaching techniques.

\section{Teaching Natural Resource Management}

Research established that environmental education in general is closely related to experiential-active and learner-centered teaching techniques (Ballantyne \& Packer, 2009; Koutsoukos, Fragoulis, \& Valkanos, 2015). 
Consequently, teaching individual modules, such as natural resources management, can lead to more integrated learning outcomes when carried out by means of learner-centered techniques such as discussion, work groups, brainstorming, case study, role play and demonstration, supported by outdoor education outside the narrow limits of the conventional classroom, such as field trips and fieldwork (Carrier, 2009). Such techniques engage students, increase their participation in the learning process and encourage the development of critical thinking and communication skills, while they promote learning through discovery and personal experience (Wurdinger \& Carlson, 2010).

More specifically, discussion within the learning process promotes critical perception, enhances the ability to express and formulate arguments and cultivates respect for other individuals' viewpoints. In the natural resource management subject, discussion can be applied to modules, in which argumentation and concerns about an environmental problem are considered useful.

In a group work approach, students are divided into small groups of 5-6 either to perform a task or to discuss a specific subject. Such a technique promotes participation, socialization and solidarity, while the teacher's role is to facilitate and support the whole process. Work groups, depending on the circumstances, can be applied to several natural resource management modules.

Brainstorming is a teaching technique, in which students bring to their mind preexisting notions freely and spontaneously, by expressing keywords/terms related to a central concept (Vassala \& Flogaiti, 2002). The teacher writes down the list of words on the board and then uses them in the learning process, classifying these words with the students' help. This technique can contribute to the introduction and explanation of new terms, as well as to the recollection of notions already known to the students. In natural resource management, brainstorming can be applied, for instance, when the teacher gives a central concept-term, such as "renewable resources" or "water resources" and then he/ she asks students to put down the first words that come to their mind on hearing these terms. Then, after being recorded, these words can be used in the learning process to further analyze the concepts at hand.

Case study, as an educational technique, is the in-depth analysis and thorough investigation of a real or virtual case or an instance, in order to draw useful conclusions. Such a technique can be an extremely interesting stimulus for discovery learning, by studying the characteristics and specificities of a case. In Natural Resource Management this technique can be widely applied, for instance, in numerous cases of sustainable or non-sustainable natural resource management that can be thoroughly studied.

Role playing is an experiential educational technique in which, under the teacher's guidance, students perform roles of a specific theme. Through role playing, an issue or problem under study or investigation can become an experience for students, activating their expressive means and critical ability. In natural resource management, role playing can be applied for instance in a discussion on the exploitation of a natural resource at a local community level.

In the demonstration technique, the teacher first introduces an object or performs a specific action; then, students are asked to repeat it under the teacher's guidance. In demonstration, which is usually applied in combination with other techniques, experiential learning is achieved through practice. Depending on the circumstances, such technique can be applied in the Natural Resource Management classroom, the school lab or even in the schoolyard.

Field trips and fieldwork transfer teaching from the conventional classroom to outdoor learning environments. This way, students are involved in several research procedures so as to observe, record and collect data, thus acquiring experience and experiential knowledge of the natural environment (Carrier, 2009). Moreover, the subject becomes a vivid process in which the idea of discovery learning is developed (Ballantyne \& Packer, 2009).

The applicability of such teaching techniques, especially in the case of Natural Resource Management, along with the difficulties involved in teaching of such an academic field, motivated further research in the present paper.

\section{Natural Resource Management in the Greek Vocational Lyceum (EPAL)}

In Greece, special interest is put on the subject of Natural Resource Management, which is optional in the Third Grade of the Greek Vocational Lyceum and is taught two hours per week throughout the school year (from September to May). Although Natural Resource Management is optional, yet a significant number of students each year choose to attend it; the subject is mainly taught by teachers with an academic background in Agronomy and Forestry. 
According to the Ministry of Education official teaching instructions the subject aims at enabling students to:

i) Broaden their knowledge on natural resources, their features and properties as well as their role in the ecosystems;

ii) Raise awareness on environmental issues and problems as a result of natural resource overuse, as well as taking action to prevent them;

iii) Develop decision-making and participation skills in environmental problem solving;

iv) Cultivate values, attitudes and behaviors for the rational natural resource management and environmental protection in general.

In order for the above mentioned teaching objectives to be achieved, the Ministry proposes the interdisciplinary and multidisciplinary approach to individual modules discussed in the textbook and the use of experiential teaching techniques. In addition, linking the subject with local environmental resource management problems in each school district, and finding ways of anticipating such problems, in order to apply knowledge to the students' everyday life, is also suggested.

Hence, the formation of a wider teaching framework that includes activities such as fieldwork and field trips to several areas such as forests, grooves, water ecosystems (e.g. lakes, rivers), parks, agricultural areas etc, is therefore recommended. This way, students can come in direct contact with nature, observe and collect numerous data, thus acquiring experience and practical knowledge on the natural resources of the environment.

\section{Method}

For the purpose hereof, the case study method was chosen, along with a small and deliberately selected sample of teachers who have taught Natural Resource Management during school year 2014-2015 in Vocational Lyceums of Northern Greece. Research was conducted on completion of the subject and more specifically in late May-early June 2015, so that teachers would have formed an opinion on the development of this subject throughout the school year.

Aiming at the fullest possible investigation, a combination of qualitative and quantitative research was used. Firstly, both unstructured and semi-structured interviews with ten teachers were conducted to explore and record their viewpoints. These interviews also aimed at highlighting key issues/ points to finalize a questionnaire applicable for quantitative research. The interviews, which were recorded, were conducted in private meetings and lasted from one to two hours.

Then, taking into account the conclusions of the qualitative research interviews, a specifically designed questionnaire, prepared in compliance with the research and literature objectives (Gray, 2014), was used. The main purpose of the questionnaire was to be scientifically adequate and comprehensive, brief and understandable, so as not to tire or repel the participants. A total of 58 questionnaires were handed out, of which 54 were returned with a rather satisfactory response rate (93.1\%). SPSS 17 software package was used for the statistical analysis of the questionnaires.

The limitations of the present study derive from the fact that on one hand the sample was small and on the other it was deliberately selected, since teachers were chosen on the basis of Judgmental or Purposive Sampling. Nevertheless, a small yet carefully selected sample is not necessarily a disadvantage for a research and can be representative of the whole (Fogelman \& Comber, 2007). Therefore, especially in cases in which the population consists of units of different accessibility, the researcher may deliberately resort to subjective selection of a representative sample, at his/her discretion, consistent with the study population profile (Fogelman \& Comber, 2007; Gray, 2014). This option, however, has the limitation of potentially limited sample representation, thus hindering the generalization of any conclusions, although often such limitations are outweighed by the researchers' accurate choice (Fogelman \& Comber, 2007).

\section{Results}

Statistical analysis of the questionnaires initially attempted to outline the participants' (teachers) profile. Out of the 54 participants, 29 were female (53.7\%) and 25 male (46.3\%), while in terms of age, 23 participants (42.6\%) were between 41-50, 18 between 31-40 (33.3\%) between 51-60 and 13 (24.1\%) (Table 1).

It is significant that out of the 54 teachers only $5(9.2 \%)$ were trained in natural resource management. As regards teaching experience in this subject, almost half of the participants $(51.9 \%)$ had between 11-15 years' experience and 14 (25.9\%) 6-10 years. On the other hand, 12 teachers (22.2\%) were relatively inexperienced in Natural Resource Management teaching and possessed only 1-5 years of experience (Table 1). 
Table 1. Participant's (teachers) profile

\begin{tabular}{lccccc}
\hline \multirow{2}{*}{ Sex } & \multicolumn{2}{c}{ Male } & \multicolumn{2}{c}{ Female } & Total \\
\cline { 2 - 5 } & \multicolumn{2}{c}{25} & \multicolumn{2}{c}{29} & 54 \\
\hline \multirow{2}{*}{ Age } & $31-40$ & $41-50$ & $51-60$ & \multirow{2}{*}{54} \\
\multirow{2}{*}{ Postgraduate Studies } & 18 & 23 & 13 & \\
\cline { 2 - 6 } & \multicolumn{2}{c}{ Yes } & \multicolumn{2}{c}{ No } & \multirow{2}{*}{54} \\
\cline { 2 - 6 } Training in Natural Resource Management & \multicolumn{2}{c}{ Yes } & \multicolumn{2}{c}{ No } & \multirow{2}{*}{54} \\
\cline { 2 - 6 } & \multicolumn{4}{c}{5} & \multicolumn{3}{c}{49} & \\
\cline { 2 - 6 } Years teaching this subject & $1-5$ & $6-10$ & $11-15$ & $>16$ & \multirow{2}{*}{54} \\
& 12 & 14 & 28 & 0 & \\
\hline
\end{tabular}

Subsequently, research focused on the teaching techniques applied by teachers in the Natural Resource Management subject. As established by the teachers' answers, the teaching technique of discussion was used by all participants $(100 \%)$. Work groups were used by $96.3 \%$, while also significantly high $(75.9 \%)$ was the percentage of case studies and field trips. Fieldwork was applied by the participants at a percentage of $72.2 \%$, demonstration at $55.5 \%$, while role playing and brainstorming at $33.3 \%$ (Table 2).

Table 2. Application of teaching techniques in natural resource management

\begin{tabular}{lcc}
\hline Teaching Technique & Frequency & Percentage \\
\hline Discussion-Dialogue & $54 / 54$ & $100 \%$ \\
Work Groups & $52 / 54$ & $96.3 \%$ \\
Case Study & $41 / 54$ & $75.9 \%$ \\
Field Trip & $41 / 54$ & $75.9 \%$ \\
Fieldwork & $39 / 54$ & $72.2 \%$ \\
Demonstration & $30 / 54$ & $55.5 \%$ \\
Role Playing & $18 / 54$ & $33.3 \%$ \\
Brainstorming & $18 / 54$ & $33.3 \%$ \\
\hline
\end{tabular}

Then, research focused on the difficulties/problems the teachers of Natural Resource Management are confronted. It was established by the qualitative research interviews that the main difficulties involved in teaching this subject is lack of updated textbooks, lack of teacher training, students' relative indifference, insufficient school facilities and teaching time limitations. Thus, by means of a five-point Likert scale participants were asked to rate the significance of each difficulty (Table 3 ). 
Table 3. Assessment of the difficulties encountered by teachers in the subject of natural resource management in 3rd grade EPAL

\begin{tabular}{|c|c|c|c|c|c|c|}
\hline Difficulty & $\begin{array}{l}\text { Not at all } \\
\text { significant }\end{array}$ & $\begin{array}{l}\text { Not Very } \\
\text { significant }\end{array}$ & $\begin{array}{l}\text { Moderately } \\
\text { significant }\end{array}$ & $\begin{array}{l}\text { Somewhat } \\
\text { significant }\end{array}$ & $\begin{array}{c}\text { Very } \\
\text { significant }\end{array}$ & Total \\
\hline $\begin{array}{l}\text { Lack of updated } \\
\text { textbooks }\end{array}$ & 0 & 4 & 10 & 15 & 25 & 54 \\
\hline Lack of training & 2 & 9 & 9 & 13 & 21 & 54 \\
\hline $\begin{array}{l}\text { Students' relative } \\
\text { indifference }\end{array}$ & 0 & 6 & 21 & 16 & 11 & 54 \\
\hline $\begin{array}{l}\text { Insufficient school } \\
\text { facilities }\end{array}$ & 4 & 12 & 24 & 8 & 6 & 54 \\
\hline Lack of teaching time & 7 & 12 & 22 & 7 & 6 & 54 \\
\hline
\end{tabular}

As regards the lack of updated textbooks, 25 participants (46.3\%) considered this a very significant difficulty, 15 somewhat significant $(27.8 \%)$ and 10 moderately significant $(18.5 \%)$, while only 4 teachers assessed such difficulty as not very significant (Table 3). It is a fact that an updated, well-written book can enhance the teaching process, being a valuable tool in the teacher's hands. The textbook of Natural Resource Management, which is used as a subject book in the Third Grade of EPAL is not entirely updated and, according to the participants, there are some rather obscure points difficult for students to digest.

Another significant difficulty involved is lack of teacher training in this subject; such difficulty is assessed as very significant by 21 participants (38.9\%) and somewhat significant by $13(24.1 \%)$. Furthermore, 9 participants described this specific difficulty as moderately significant (16.7\%), 9 as not very significant (16.7\%) and only 2 not significant at all (3.7\%) (Table 3). Although at times, some teacher training on environmental education-especially on natural resource management-does take place, nonetheless it is fragmentary and non-recurring, thus inadequately satisfying the teacher training needs. Moreover, underlining the findings in Table 1, a very small percentage of participants-teachers (9.2\%) was trained in this subject.

In any case, undoubtedly teacher training is a lifelong process of decisive significance in quality teaching (Avalos, 2011). It is linked with formal and informal learning activities, supported by several forms of training and is interwoven with the personal development and upgrading of previous experience through critical reflection processes and transformative learning.

As stressed by teachers themselves in the qualitative research interviews, students developed a relative indifference for the Natural Resource Management subject. Such indifference derives from the fact that on the one hand Third Grade comprises other subjects significant for the final exams, while on the other hand, students are fully oriented towards their entrance exams in higher education, which this lesson is not part of. Out of the 54 participating teachers, $11(20.4 \%)$ described this indifference as a very significant difficulty and $16(29.6 \%)$ as somewhat significant; 21 participants $(38.9 \%)$ considered this difficulty as moderately significant, while only 6 teachers $(11.1 \%)$ characterized it as not very significant (Table 3 ).

More or less equivalent were the teachers' answers regarding the assessment of the last two difficulties, i.e. insufficient school facilities and the lack of teaching time. Insufficient school facilities concerns laboratories and classrooms equipped with state-of-the-art teaching aids. Only six participants $(11.1 \%)$ considered such difficulty as very significant and 8 as somewhat significant $(14.8 \%)$, while 24 participants thought it was moderately significant $(44.4 \%)$. On the other hand, 12 teachers $(22.2 \%)$ considered insufficient school facilities as not very significant difficulty and 4 (7.4\%) as not significant at all (Table 3 ).

Lack of teaching time was another difficulty involved and reported by teachers. It should be underlined that the subject is taught two hours per week and in Third Grade timeframe is relatively limited, since it is important for students to prepare for their higher education entrance exams. 6 participants considered this difficulty as very significant $(11.1 \%)$ and 7 somewhat significant (13\%), while 22 moderately significant $(40.7 \%)$. Finally, 12 participants $(22.2 \%)$ considered lack of teaching time as not very significant and seven $(13 \%)$ no significant at all (Table 3). 


\section{Conclusions-Suggestions}

Through the case study of the Natural Resource Management subject in Greek Vocational Lyceum, an investigation of teaching techniques and the assessment of the difficulties faced by teachers in teaching this subject were attempted.

A key conclusion is that teachers effectively apply some learner-centered techniques such as discussion, work groups, case study, field trip and fieldwork; to a lesser extent they apply some other techniques, such as demonstration, role playing and brainstorming. Obviously, choosing and applying a teaching technique over another is dictated by several parameters and depends on the circumstances. One of the factors influencing the teaching approach is also the difficulties faced in everyday learning process.

As regards the difficulties/problems, with which teachers in Natural Resource Management are confronted, it was established that the major difficulties involved were lack of updated textbooks and lack of teacher training in this field.

Lack of updated textbooks is a major issue for the majority of the Greek Vocational Lyceum subjects. Most books were written in the $90 \mathrm{~s}$ and have not been updated ever since. Thus, there might be a new edition every couple of years, but in fact it is nothing more than mere reprint of old editions, without any new information and data meanwhile emerging. According to participants this is the case of the Natural Resource Management textbook. Thus, either an updating of the existing textbook with new data and information could be suggested or compiling a new book sufficiently well written and rather enriched, as compared to the existing one.

Regarding the lack of teacher training in the subject, as indicated by the research, those who teach this very subject in Greek Vocational Lyceum are agronomists and foresters, the vast majority of whom have not received any specialized training in natural resource management. Consequently, it can be maintained that some of them do not feel sufficiently trained to fully meet the teaching requirements of such a topic. It could be suggested that at the beginning of each school year, teachers undertaking this lesson attend a fast-track training course which will improve their knowledge on natural resource management.

As far as the students' relative indifference for this subject is concerned, more frequent application of experiential and learner-centered teaching techniques could be suggested. Also, the implementation of targeted field trips and well organized fieldwork would attract students' interest.

Although lack of teaching time is not considered as the most significant difficulty, however Natural Resource Management subject could have better learning results if taught in the Second Grade rather than the Third. Second Grade is neither characterized by stress for the upcoming higher education entrance exams nor is teaching time limited so as to hinder the application of experiential teaching techniques and conducting field trips and field work. Eventually, insufficient school facilities do not seem to constitute a major problem, since recently school facilities have been considerably improved in most Greek Vocational Lyceums.

To conclude with, the case study presented in this paper contributes to the understanding of teaching techniques and the difficulties involved in teaching Natural Resource Management in the Greek Vocational Lyceum. Further research would more thoroughly investigate this issue, at the same time focusing on some of its other dimensions as well, such as learning results or learning evaluation models.

\section{Acknowledgments}

The authors would like to thank the 54 participating professors for their cooperation and willingness to respond to the present research. In addition, the authors would like to thank the editor and the reviewers of this journal for their valuable comments on an earlier version of this manuscript.

\section{References}

Avalos, B. (2011). Teacher professional development in Teaching and Teacher Education over ten years. Teaching and Teacher Education, 27(1), 10-20. http://dx.doi.org/10.1016/j.tate.2010.08.007

Ballantyne, R., \& Packer, J. (2009). Introducing a fifth pedagogy: Experience-based strategies for facilitating learning in natural environments. Environmental Education Research, 15(2), 243-262. http://dx.doi.org/10.1080/13504620802711282

Carrier, S. (2009). Environmental Education in the Schoolyard: Learning Styles and Gender. The Journal of Environmental Education, 40(3), 2-12. http://dx.doi.org/10.3200/JOEE.40.3.2-12

Dimitriou, A. (2009). Environmental Education: Environment, Sustainability: Theoretical and pedagogical approaches. Thessaloniki: Epikentro Publications (in Greek) 
Fogelman, K., \& Comber, C. (2007). Surveys and Sampling. In A. R. J. Briggs, \& M. Coleman (Eds.), Research Methods in Educational Leadership and Management (pp. 125-141). London: Sage Publications.

Gray, D. (2014). Doing research in the real world (3rd ed.). London: Sage

Gylfason, T. (2001). Natural Resources, Education and Economic Development. European Economic Review, 45(4-6), 847-859. http://dx.doi.org/10.1016/S0014-2921(01)00127-1

Jones, G. (2003). People and Environment. London: Routledge.

Koutsoukos, M., Fragoulis, I., \& Valkanos, E. (2015). Connection of Environmental Education with Application of Experiential Teaching Methods: A Case Study from Greece. International Education Studies, 8(4), 23-28. http://dx.doi.org/10.5539/ies.v8n4p23

Littledyke, M. (2008). Science education for environmental awareness: approaches to integrating cognitive and affective domains. Environmental Education Research, 14(1), 1-17. http://dx.doi.org/10.1080/13504620701843301

Michail, S., Stamou, A., \& Stamou, P. (2007). Greek primary school teachers' understanding of current environmental issues: An exploration of their environmental knowledge and images of nature. Science Education, 91(2), 244-259. http://dx.doi.org/10.1002/sce.20185

Vassala, P., \& Flogaiti, E. (2002). Brainstorming as a teaching technique for approaching environmental problems. Proceedings of 1st Environmental Conference of Macedonia, Thessaloniki (March 1-4, 2002, pp. 444-450). Retrieved from http://mathslife.eled.uowm.gr/sites/default/files/usersfiles/Kategismos\%20ideon. pdf

Voutsinos, G., Kalkanis, G., Kosmas, K., \& Soutsos, K. (2003). Natural Resource Management. Athens: Ministry of Education (in Greek)

Wurdinger, S. D., \& Carlson, J. A. (2010). Teaching for Experiential Learning. Five Approaches that Work. Rowman and Littlefield Inc. Retrieved from http://dx.doi.org/10.1037/10762-000

\section{Notes}

Note 1 . As determined by virtue of the prot. No. 74920/Г2/10-06-08 Ministerial Decree (GG Issue 1210/II).

\section{Copyrights}

Copyright for this article is retained by the author(s), with first publication rights granted to the journal.

This is an open-access article distributed under the terms and conditions of the Creative Commons Attribution license (http://creativecommons.org/licenses/by/3.0/). 